
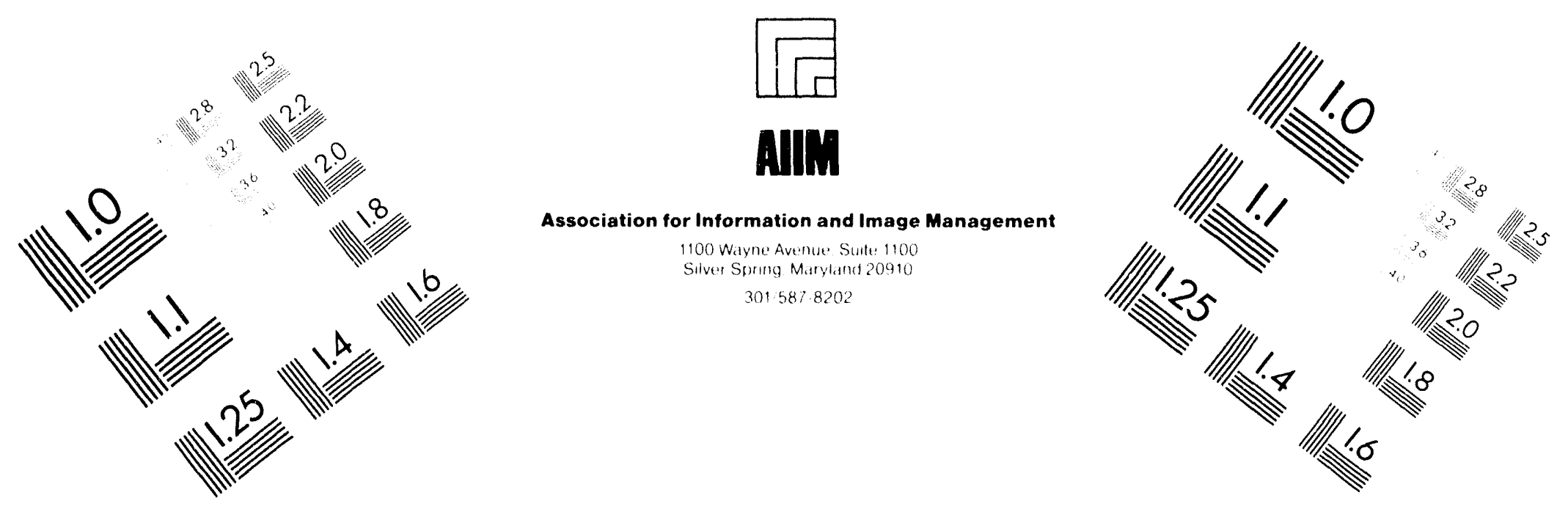

\title{
Centimeter
}

|m

Inches
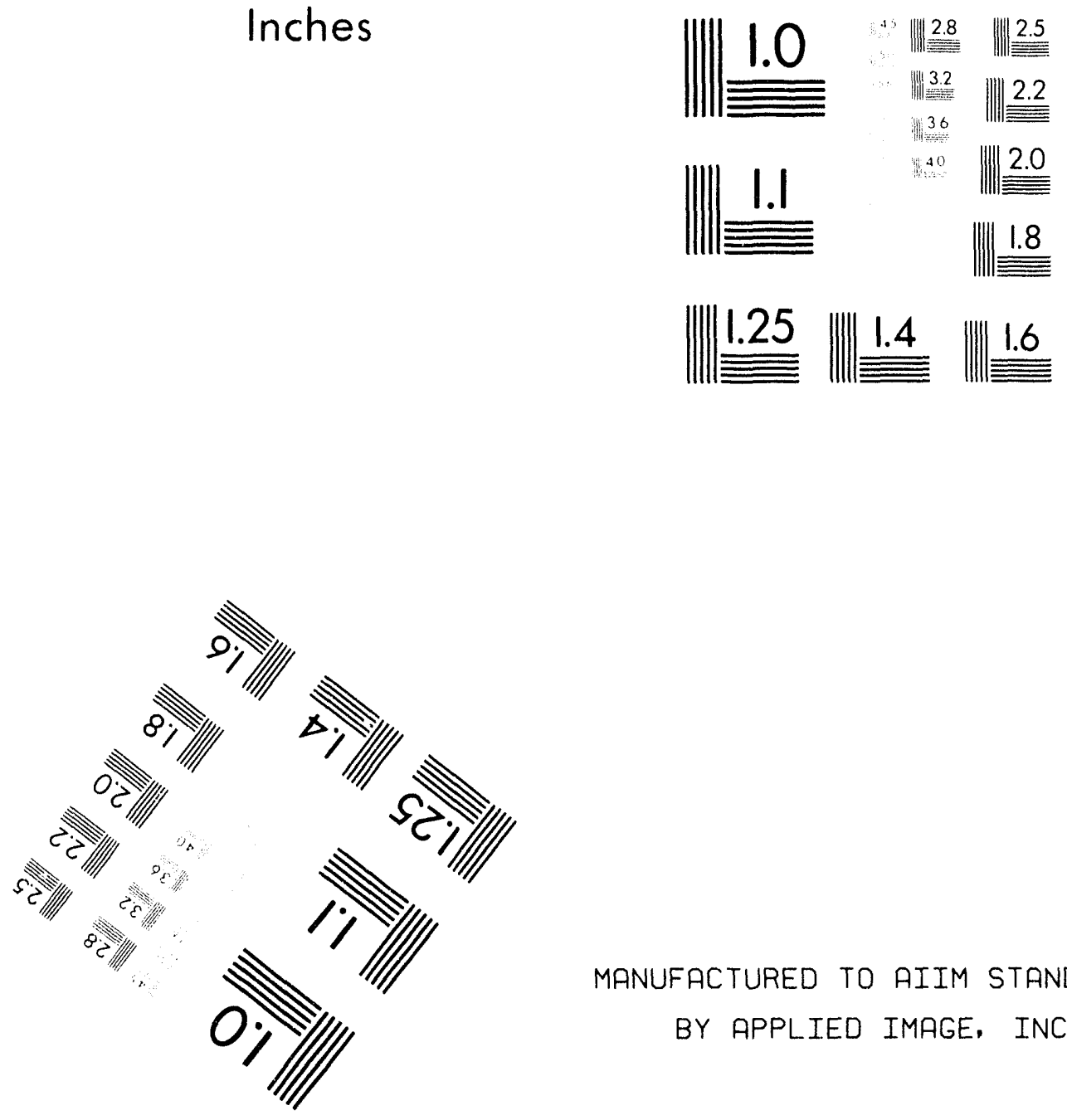

MANUFACTURED TO AIIM STANDARDS

BY APPLIED IMAGE, INC.

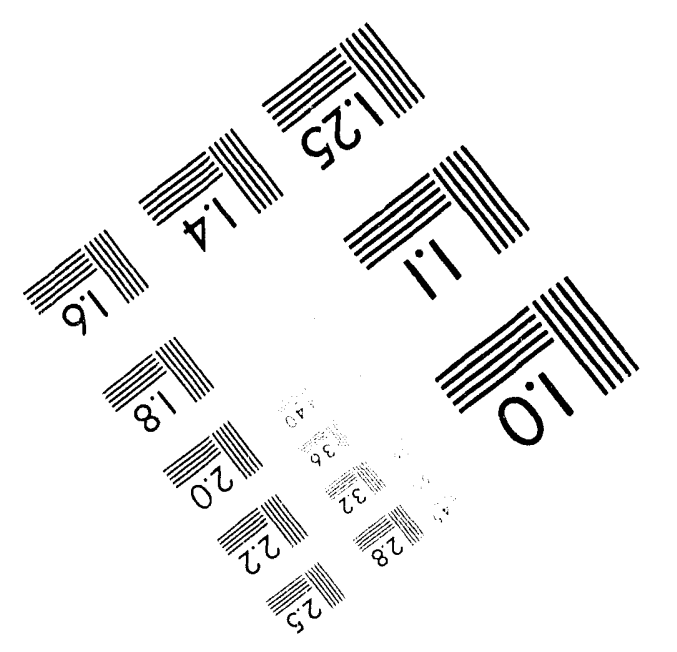



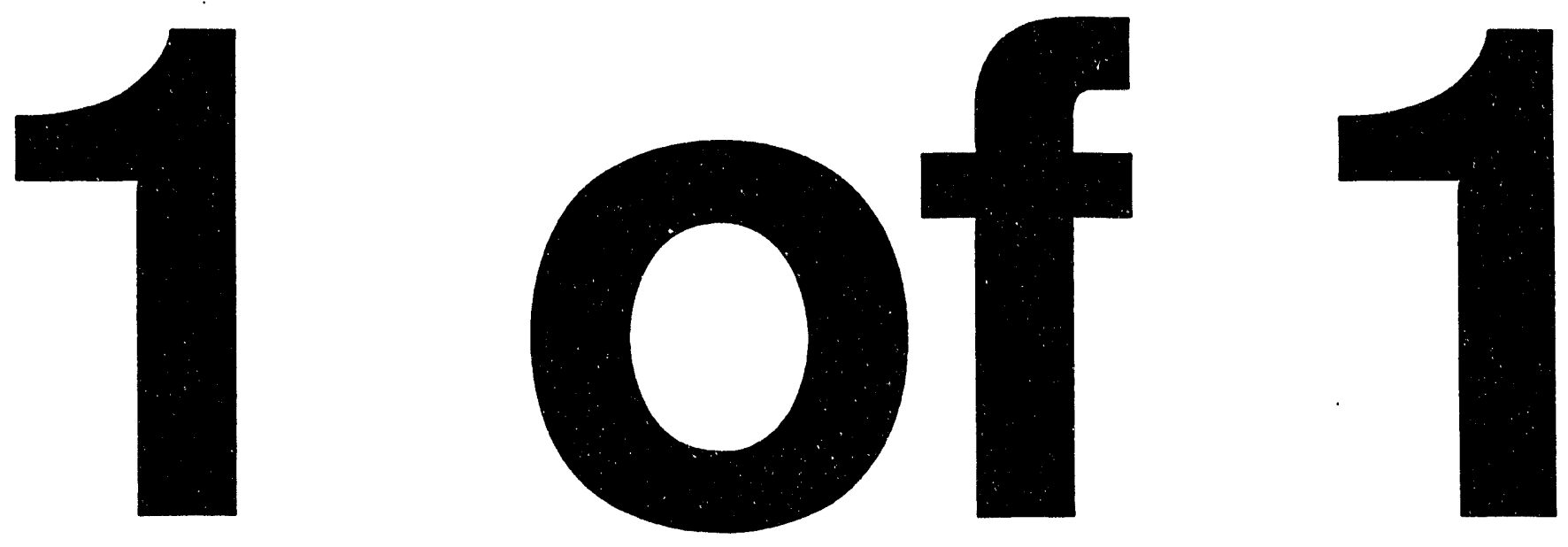


\title{
$\operatorname{Con} .940552--8$
}

UCRL-JC-116269

PREPRINT

\section{Motional Stark Effect Upgrades on DIII-D}

\author{
B.W. Rice, D.G. Nilson, and D. Wroblewski
}

This paper was prepared for submittal to the 10th Topical Conference on High-Temperature Plasma Diagnostics Rochester, NY

May 8-12, 1994

April 1994

This is a preprint of a paper intended for publication in a journal or proceed ings. Since changes may be made before publication, this preprint is made available with the understanding that it will not be cited or reproduced without the permission of the author.
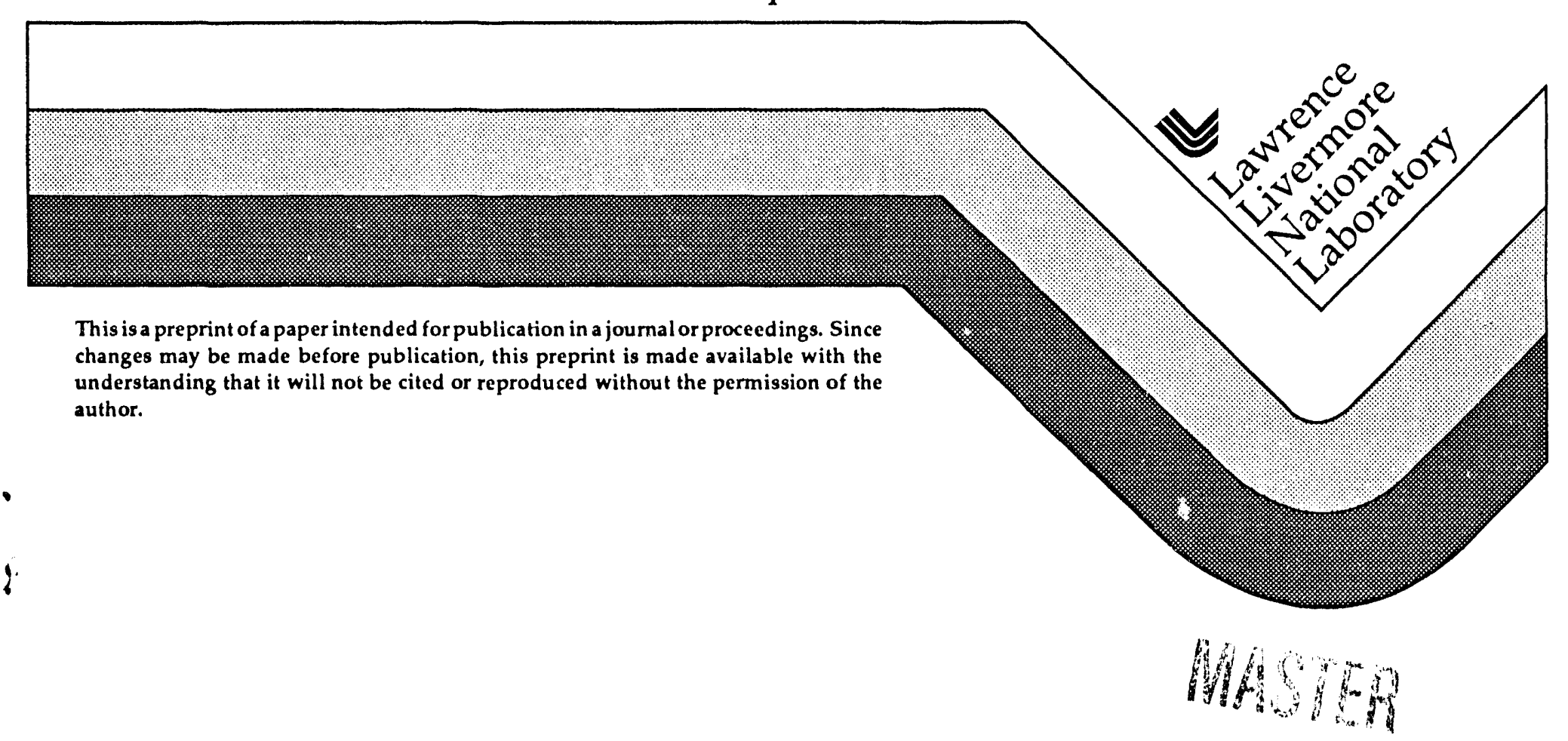


\section{DISCLAIMER}

This document was prepared as an account of work sponsored by an agency of the United States Government. Neither the United States Government nor the University of California nor any of their employees, makes any warranty, express or implied, or assumes any legal liability or responsibility for the accu racy, completeness, or usefulness of any information, apparatus, product, or process disclosed, or represents that its use would not infringe privately owned rights. Reference herein to any specific commercial products, process, or service by trade name, trademark, manufacturer, or otherwise, does not necessarily constitute or imply its endorsement, recommendation, or favoring by the United States Government or the University of California. The views and opinions of authors expressed herein do not necessarily state or reflect those of the United States Government or the University of Califomia, and shall not be used for advertising or product endorsement purposes. 


\title{
Motional Stark Effect Upgrades on DIII-D*
}

\author{
B. W. Rice. D.G. Nilson, D. Mróblewsti" \\ Lawrence Livermore National Laboratory \\ Prepared for Submission to \\ Proceedings of the Tenth Topical Conference \\ on High-Temperature Plasma Diagnostics \\ May 1994
}

\section{Abstract}

The measurement and control of the plasma current density profile (or $q$ profile) is critical to the advanced tokamak program on DIII-D. A complete understanding of the stability and transport properties of advanced operating regimes requires detail poloidal field measurements over the entire plasma radius from the core to the edge. In support of this effort, we have recently completed an upgrade of the existing MSE diagnostic, increasing the number of chamnels from 8 to 16. A new viewing geometry has been added to the outer edge of the plasma which improves the radial resolution in this region from $10 \mathrm{~cm}$ to $<4 \mathrm{~cm}$. This view requires the use of a reflector that has been designed to minimize polarization amplitude and phase effects. Vacuum-compatible polarizers have also been added to the instrument for in-situ calibration. Future use of the MSE diagnostic for feedback control of the q profile will also be discussed.

\section{Introduction}

The measurement of poloidal fields using the motional Stark effect is a well established diagnostic technique that has been implemented on several tokamaks $[1,2,3]$. In brief, the measurement relies upon the splitting of the neutral beam Balmer- $\alpha$ line $\left(D_{a}\right)$ into orthogonally polarized components $(\sigma, \pi)$ due to the motional $\mathbf{E}=\mathbf{v} \times \mathbf{B}$ electric field. When viewed in a direction perpendicular to $\mathbf{E}$. the Stark $\sigma$ and $\pi$ components are polarized perpendicular and parallel to the direction of the electric field respectively. By measuring the polarization of the Stark $\sigma$ component, the local pitch angle of the magnetic field $B_{v} / B_{\iota}$ can be deduced.

An 8 channel Motional Stark Effect (MSE) diagnostic has been operational for two years now on DIII$D$ [1]. The instrument was originally designed for op- timum radial resolution of $\sim 2 \mathrm{~cm}$ in the core, but has poor resolution of $\sim 10 \mathrm{~cm}$ near the edge. After examining the equilibrium reconstructions for several different $J$ profile shapes relevan to the advanced tokamak program on DIII-D, and performing error analysis using MSE data. we concluderd that several improvements to the MSF diagmextic could be made which would benefit our program. These include: 1) improving the radial resolution near the outer edge: 2) increasing the number of measiureneme chords; and 3) reducing systematic arors throngh inproved cal. ibration techniques. To address these concerns. We have added an additional 8 MSE chords (called edge ISE) to the outside $30 \mathrm{~cm}$ of the plasma. using a new. viewing geometry that improves the radial resolution in this region.

\section{Measurement Geometry}

The performance of the MSE diagnustic depends sensitively on the intersection angles between the collection optics line-of-sight. the neutral beam. and the toroidal field. Three criteria must be satisfied for $\mathrm{er}$ ery MSE chord: 1) the optical line-of-sight must be nearly tangent to the toroidal field for optimum radial resolution: 2) the angle between the optics lineof-sight and the neutral beam must be sufficient to give a large enough Doppler shift to clearly separate the full beam energy Stark spectrum from thermal $D_{a}$, impurity liness, and the $1 / 2$ and $1 / 3$ beam ellergy spectra: and 3) the iinduced $v \times B$ alectric field muse be large enough to provide sulficienth separatlont between the $\sigma$ and $\pi$ lines.

The original multichord MSE system on DIII-D had 8 chords ranging from near the vessel center at $\mathrm{R}=155 \mathrm{~cm}$ to near the plasma edge at $\mathrm{R}=228 \mathrm{~cm}$. Referring to the geometry shown in Fig. 1. the radial resolution is given approximately by $\delta R$ $(d+w \sin \Omega 2 i / \sin (\Omega 2+\alpha)$ where $d$ is the upucal spot 
size, and $w$ is the beam width. This function is plotted in Fig. 2 for the existing. MSE system (solid line), which shows poor resolution outside of $R \sim 195 \mathrm{~cm}$. To improve this situation we have added 8 additional chords viewing from a midplane port at a toroidal angle of $45^{\circ}$ as shown in Fig. 1. The view from this port is nearly tangent to $B_{t}$ at the plasma edge, thus giving good radial resolution as shown by the dotted line in Fig. 2. The original .ISE chords (now called central) have been realigned (owards the plissila core cover the radial range $155 \mathrm{~cm}<R<200 \mathrm{~cm}$, while the edge system covers $200 \mathrm{~cm}<R<230 \mathrm{~cm}$. This gives a channel spacing of about $4-5 \mathrm{~cm}$, with a resoluticn for each channel better than $5 \mathrm{~cm}$ over the entire measurement range. No chords are located inside of $R=155 \mathrm{~cm}$ due to excessive beam attenuation.

The maximum angle 0 between the optical sightline and the neutral beam is $60^{\circ}$ for this view, which is sufficient to separate the $75 \mathrm{keV}$ full-energy Stark spectrum from the $1 / 2$ and $1 / 3$ beam energy spectra. However, there are two strong carbon impurity lines located at $6578 A$ and $6583 \mathrm{~A}$ which interfere with the 'red-shifted' $D_{a}$ line (there are no impurity' lines in the 'blue-shifted' direction of the central MSE chords). A typical plasma spectrum obtained using the CER spectrometer is shown in Fig. 3 for a deuterium beam energy of $75 \mathrm{keV}$. This spectra would simulate that of an MSE chord viewing the edge at $R=228 \mathrm{~cm}$ from the $45^{\circ}$ port. Lnder these conditions, the full-energy Stark $\sigma$ line is clearly separated from the CII impurity lines. These impurity lines would, however, interfere with the VSE measurement at beam energies of $65 \mathrm{keV}$ or lower.

The separation of the $\sigma$ and $\pi$ components (proportional to $\mathbf{v} \times \mathrm{B}$ ) has also been calculated for the edge MSE geometry and is found to be sufficient for toroidal fields of $0.8 \mathrm{~T}$ or greater.

\section{Edge MSE Design}

Details of the light collection optics for the edge MSE instrument are shown in Fig. 4. The design is complicated by the need to have a reflector located close to the plasma surface. A similar problem was encountered on TFTR [3]. A property of all metal reflectors is that the $s$ and $p$ polarizations reflect with different amplitude and phase depending on the angle of incidence [4]. This effect is a serious problem because it can lead to a rotation of the incoming polarization and also polarizes the background plasma light. In principle, if the reflection amplitudes and phase are measured for a given reflector. and the background light level is monitored, then these effects can be cor- rected $|3|$. However. these corrections are guite sensistive to reflector surface coatings and may vary durme plasma operation.

Two options wr.re investigated for elimunating polarization effects upon reflection: an internally reflecting prism and a multilayer dielectric reflector The prism has the advantage that the reflectance for the $s$ and $p$ polarizations is 100 percente for all inter-

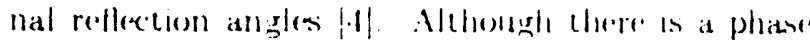

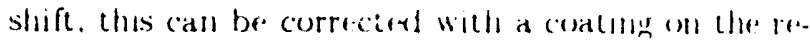
flecting surface i5: Becallse of the large path length through glass, the prism must be manufactured from a zero Verdet constant glass such as Schote SFL6 or SFL56 6$\}$. Lnfortunatel:: these glasses all exhibit a large thermal expansion coefficient and thermal stress calculations indicate that the prism would be suscept tible to stress fractures during baking. Instead we opted for a multilayer dielectric coated reflectur $|i|$. consisting of alternating layers of flused silicat and talltalum pentoxide deposited on a fused silica substrate The fused silica substrate offers excellemt stabilits during thermal cycling. Design calculations for angles of incidence between $4 x^{\circ}$ and $6 x^{\circ}$ indicate that the $s$ and $p$ reflection amplitudes are equal to within $1 \%$, with the phase shift between the two polarizations being held to less than 15 degrees. Bench tests of the actual reflector confirmed these specifications. As illustrated in Fig. 4. the reflector is protected from coatings and plasma damage by a carbon tile on one side and a $2 \mathrm{~mm}$ thick fused silica shield on the viewing side. Thin coatings on the flused silica

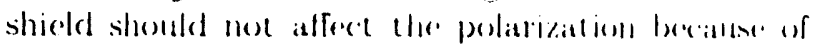
the near normal angle of micidence.

There are two shutters incorporated into the design. The outer shutter is a carbon sheld designed to protect the optics during helium glow wall conditioning between shots. The inside shutter has been fitted with four $2.4 \times 3 \mathrm{~cm}$ polarizers $|8|$ to be used for calibration. These polarizers are vacuum compatible, consisting of a BKT substrate with imbedded silver wires. The polarizer shutter can be inserted during plasma operations to provide an m-situ offset calibration.

The vacuum window is quite large at 5.5 inches in diameter. Bench measurements indicate that there is a snaall level of stress birefringence present in the w'Indow, but this can be accounted for in the instrument calibration. The three lenses are $11 \mathrm{~cm}$ in diameter and combine to give a demagnification of 10 . To avoid Faraday rotation effects they are manufactured from Schou SFL6 glass. For each channel. the lenses image onto an array of six $1 \mathrm{~mm}$ diameter fibers stacked vertically: corresponding $t 0$ a $1 \mathrm{~cm}$ wide by $8 \mathrm{~cm}$ high inage in the plasima. 
The remainder of the edge MSE instrument de sign external to the vessel Hig $\bar{y}$, is is quite similar to the original system describud in Ref. |1|. The lenses focus light through two photoeliastic modnlators (PEM) and a sheet polarizer onto the array of fiber optics. The modulators operate at $20 \mathrm{kHz}$ and $23 \mathrm{kHz}$. At the fiber output. the light is collimated, passed through a 3 A bandpass filter, and focused onto a Hamamatsu R636 photomultiplier tube. Two lock-in amplifiers detect the 2nd harmonic of each PEM frequency, which are approximately pro portional to the sine and cosine of the polarization pitch angle $\gamma$. One notable difference in design compared with the original MSE instrument is that the Wollaston prism used to collect both polarizations as described in |1| has been replaced with a simple sleee polarizer. This reduces the number of photomultipliers to one per channel rather than two and simplifies the entire design. The signal level is maintained by using a total of six fibers to collect a single polarization, rather than three fibers for each polarization as used previously:

\section{Future Work}

During the next experimental campaign on DIII-D. we will make the first attempts at feedback control of the on-axis safety factor $q_{0}$ using . ISE. In preparation for this, we have installed analog fiber optic links to transmit both the $\sin \gamma$ and $\cos$ ? lock-in signals to an HP workstation dedicated for feedback control. The workstation will digitize all of the magnetic loop and MSE signals real-time and provide feedback signals to non-inductive current drive sources such as neutral beams or fast wave. Algorithms for calculating parameters such as $y_{0}$ directly from the MSE data are being developed.

\section{Acknowledgement}

-Work supported under US DOE by LLNL Contract W-7405-ENG-48 and General Atomics Contract DEAC03-84ER51044.

\section{References}

(1) D. Wroblewski and L.L. Lao. Rev. Sci. Instrum. 63, 5140 (1992).

(2) F.M. Levinton, et al, Rev. Sci. Instrum. 61, 2914 (1990).

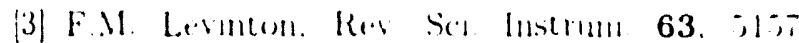
(1992)

(4) F.A. Jenkuns and H E. Whate. Fundesmentals of Optics. McGraw-Hill. Inc. Vou York. 1976

5), P. Mauer. J. Opt Soc. Am. 56. 1219:1966;

66 Schot Class Technical Information Bulletin Vin 17 (198\%)

(7) Reflector manufactured by Opcical ( odating Lals oratory Inc., Santa Rosia. C.I

$|8|$ Polarizers manufactured by (omming Incorper rated. Corning. II Y

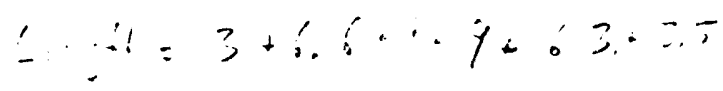

$$
\begin{aligned}
& =3 \div .4^{\circ} /
\end{aligned}
$$




\section{Figure Captions}

1. Overview of the upuraded 16 chord MSL system viewing geometry on DIII-D

2. Radial resolution versus radial position for the central and edge MSE viewing geometry

3. Red-shifted Stark spectra and CII impurity lines at a beam energy of $75 \mathrm{keV}$

4. Edge .MSE collection optics.

5. Overview of the edge MSE detection sistem 


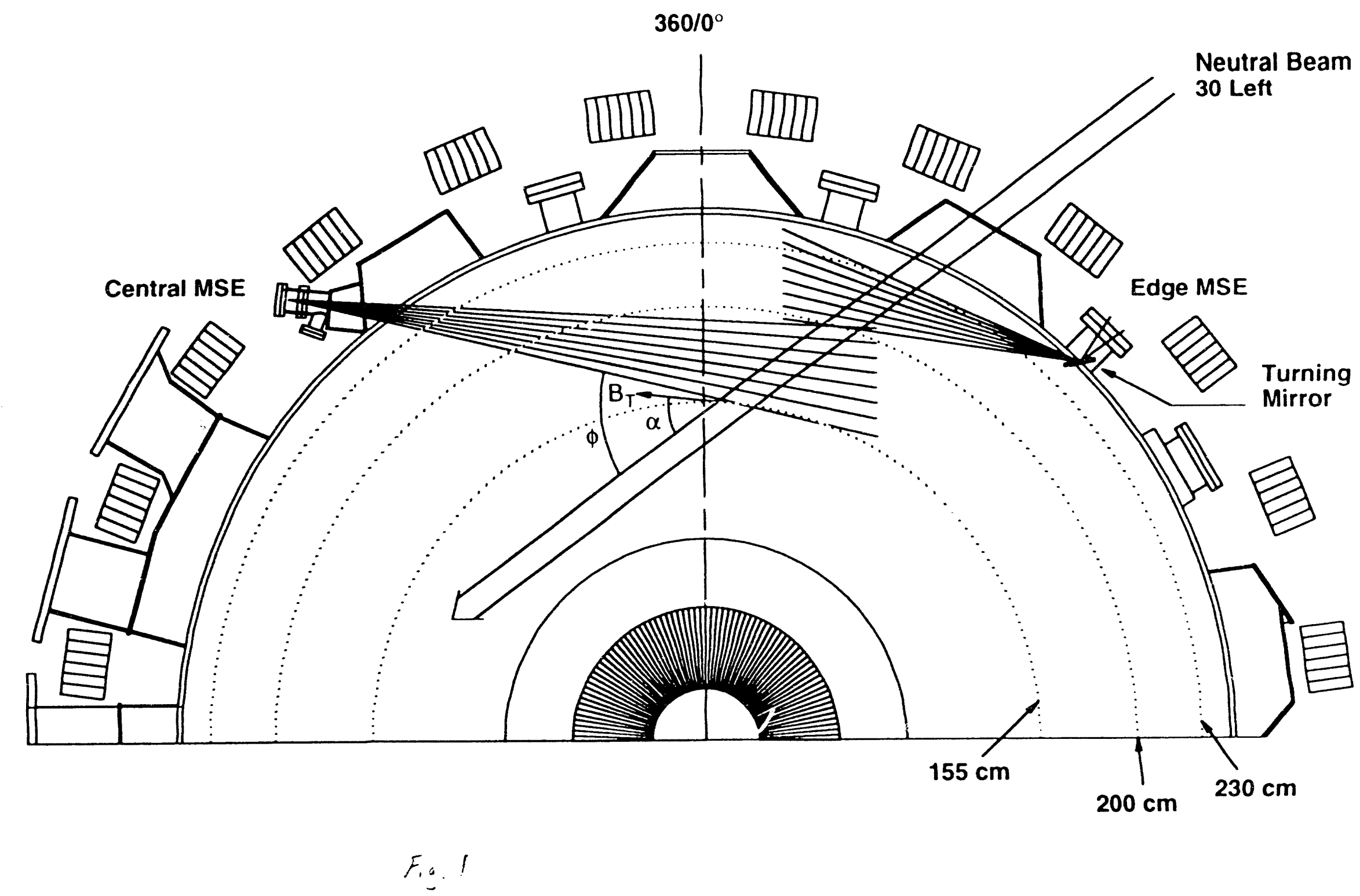




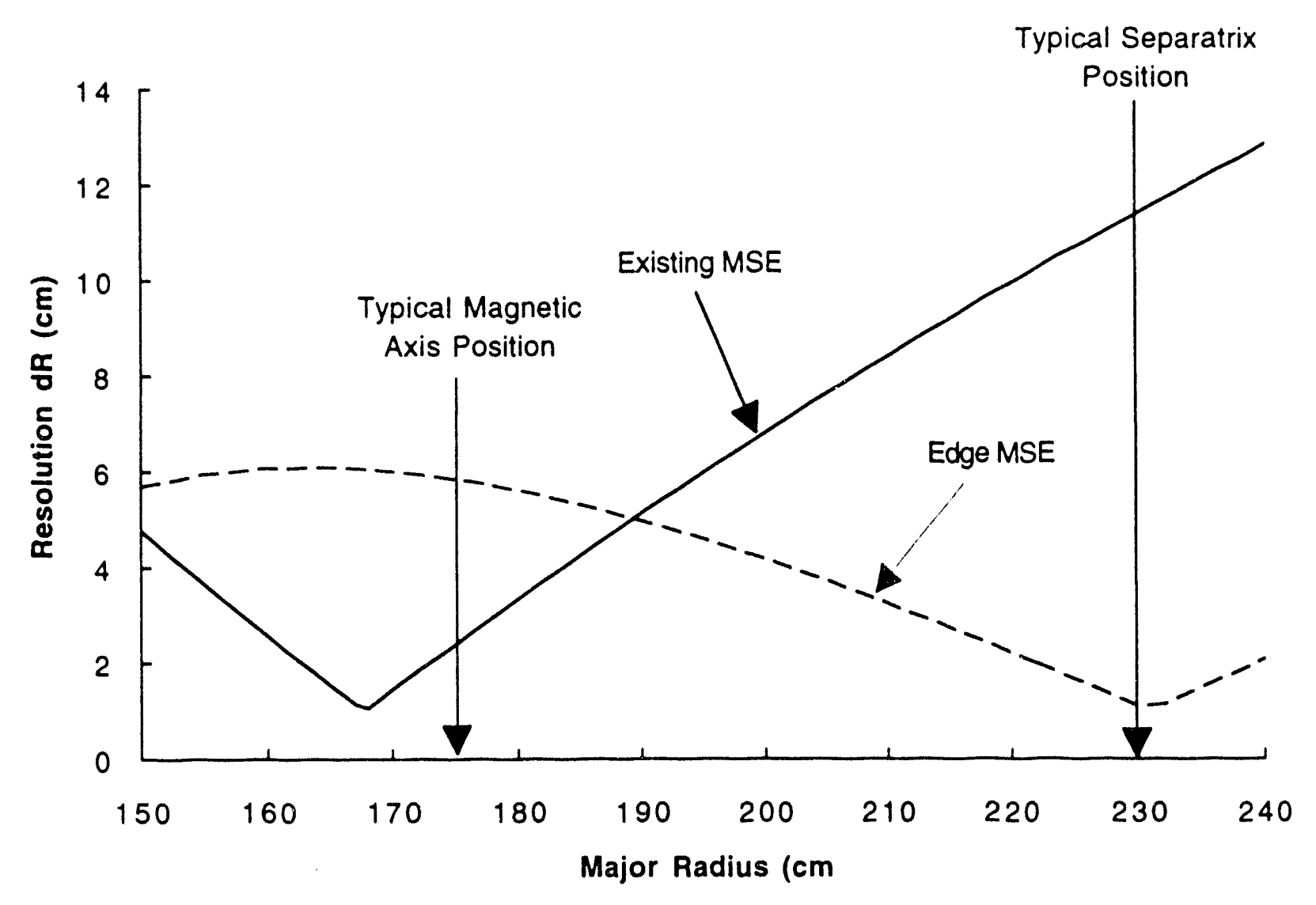

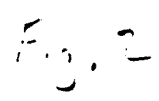



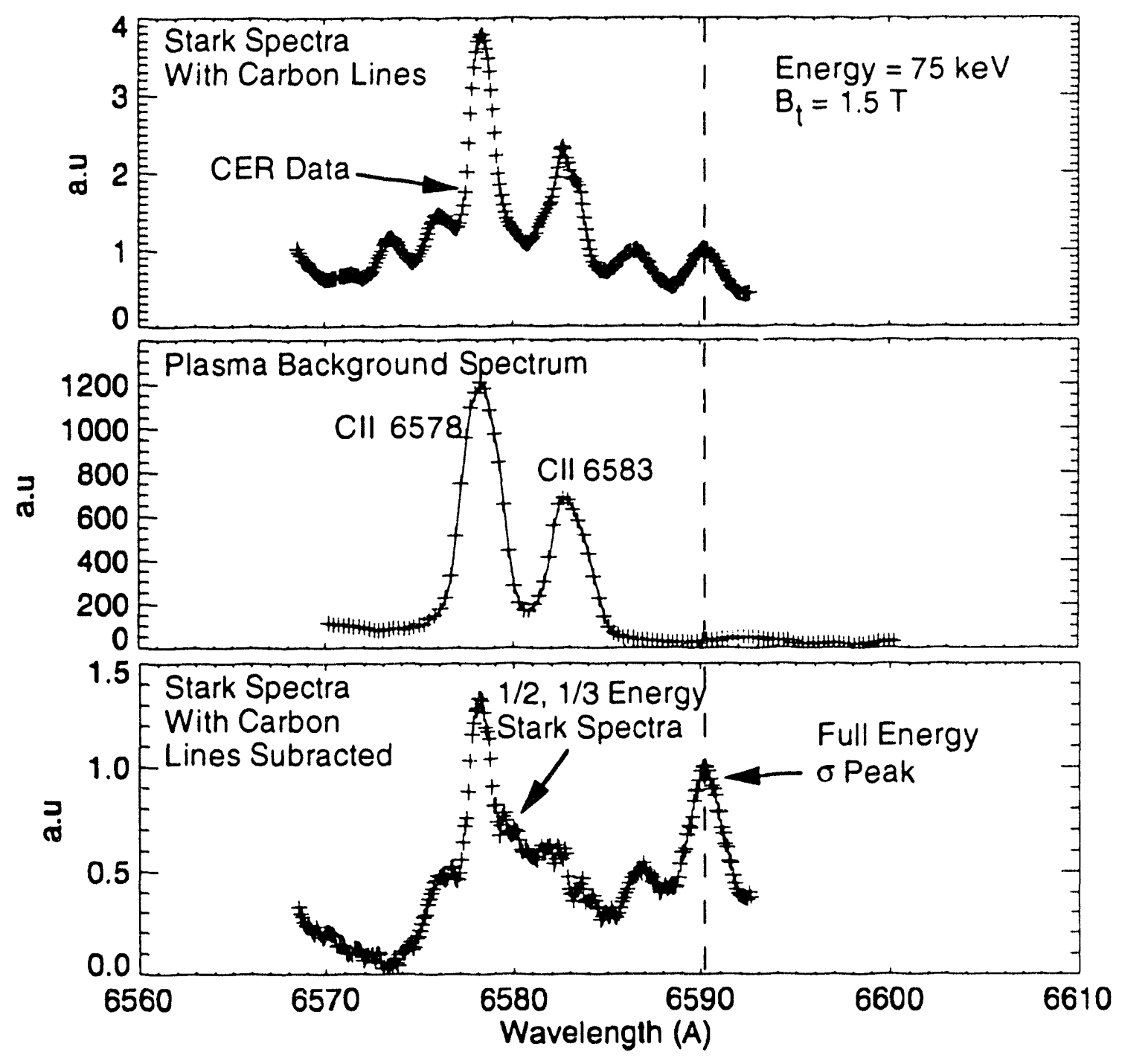

1.0 .3 


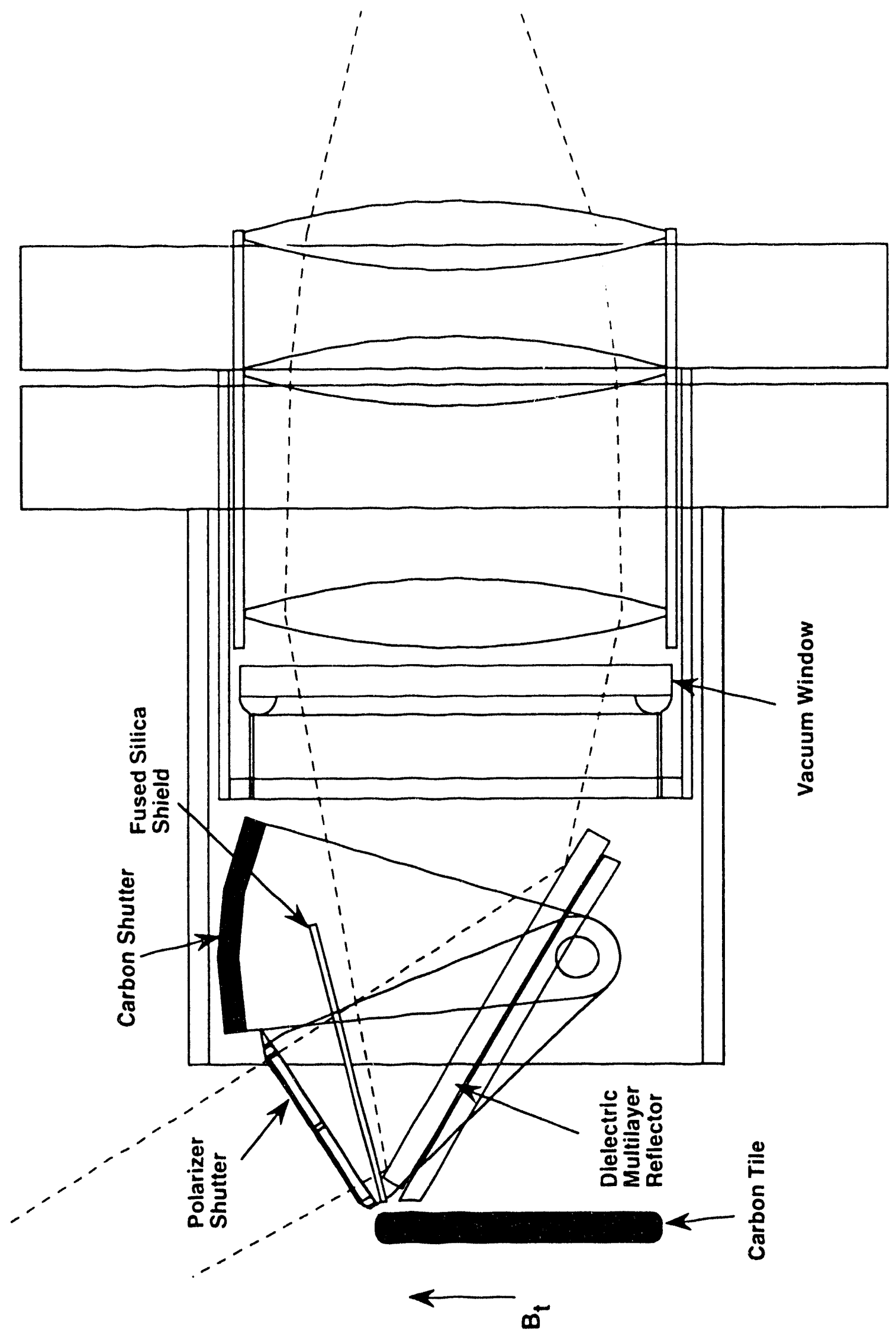

7
$\therefore$ 


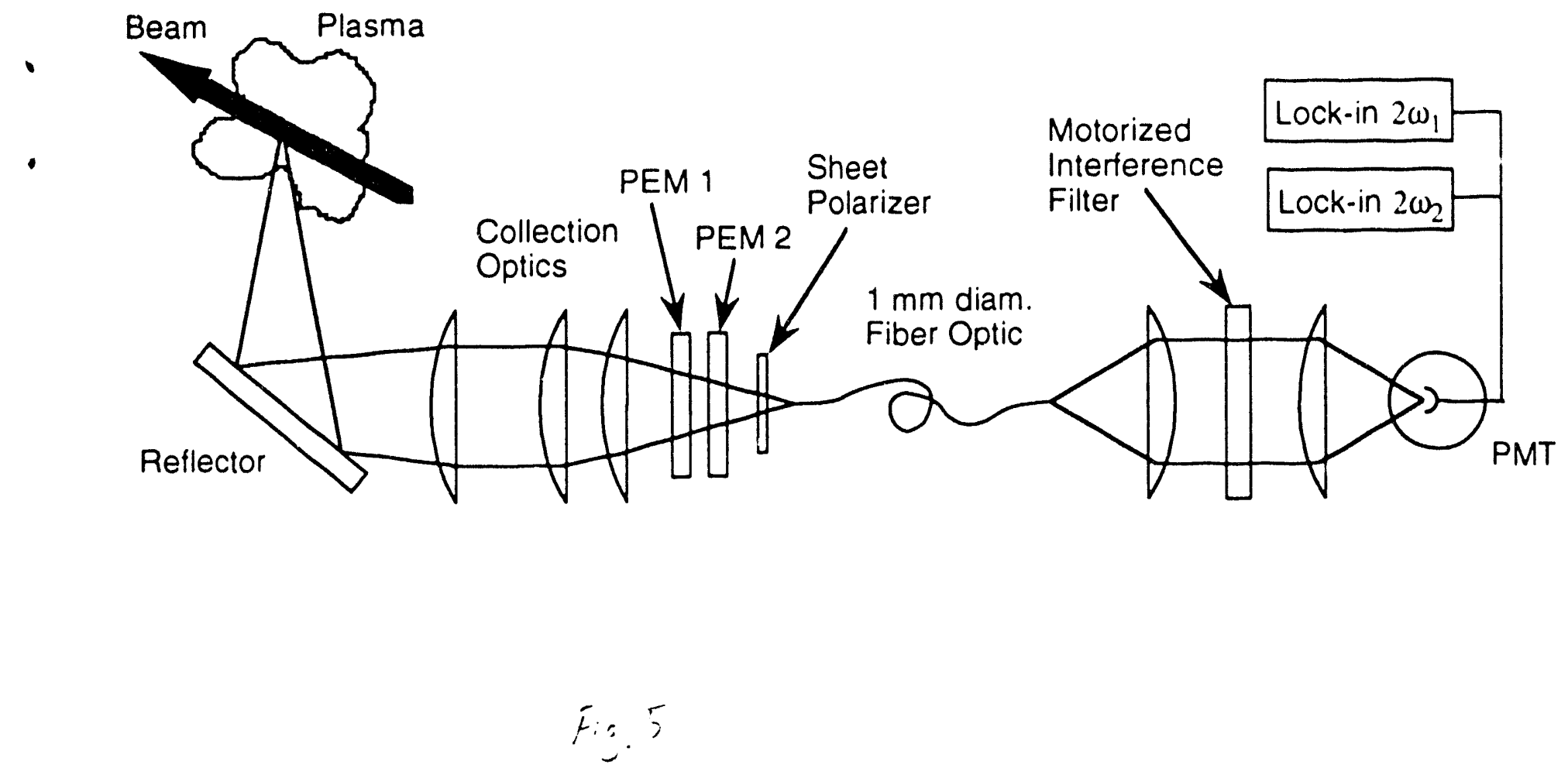



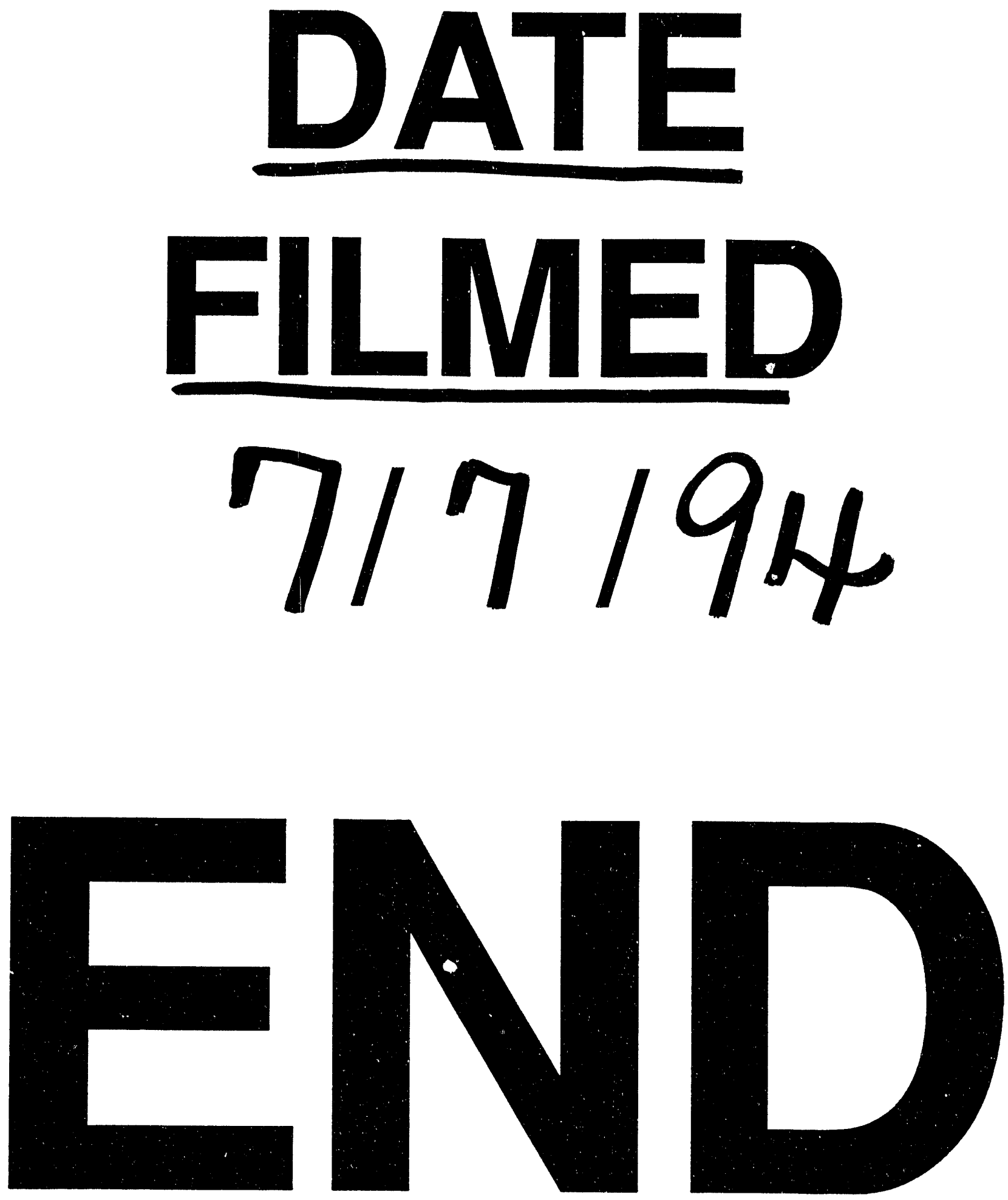
